ABDIMASKU, Vol. 2, No. 1, Januari $2019: 28-33$

\title{
Pembuatan Acara Live Streaming "Joox Live Now" Sebagai Bentuk konten Radio di Era Digital
}

\author{
Calvin Sharon Mongkol ${ }^{1}$, Aditya Nugroho Pratomo², Dhita Widya Putri ${ }^{3}$ \\ ${ }^{1,2,3}$ STIKOM The London School of Public Relations Jakarta \\ e-mail: ${ }^{* 1} \underline{\text { calvin.mongkol@ gmail.com, }}{ }^{2} \underline{\text { aditya.nugroho.p@gmail.com, }}{ }^{3}$ dhita.wp@1spr.edu
}

\begin{abstract}
Abstrak
Perkembangan teknologi dan komunikasi telah membawa banyak perubahan, khususnya dalam industri media penyiaran. Semenjak hadirnya internet, orang-orang dapat mendengarkan musik melalui berbagai portal yang diakses melalui telepon pintarnya. Tren ini dikenal dengan konvergensi media, dimana terjadi persilangan antara teknologi internet dengan dengan radio analog. Lahirnya konvergensi media dalam industri radio juga memunculkan istilah streaming, yaitu konten yang disiarkan langsung melalui internet, berupa audio maupun video. Salah satu penyedia layanan radio streaming di Indonesia adalah JOOX. Perancangan ini dibuat dengan tujuan untuk memberikan gambaran dan kontribusi di era media baru, khususnya pada industri musik dan radio dengan konsep online strategy dalam music radio programming dari Newton dan Kaiser. Hasil dari karya ini adalah JOOX merupakan acara live streaming audio visual yang memfasilitasi para musisi untuk mempromosikan album barunya, serta ajang untuk saling berinteraksi dengan penggemarnya lewat fitur livechat sebagai wujud dari engagement.
\end{abstract}

Kata Kunci-konvergensi media, industri radio, industri musik, internet, live streaming

\begin{abstract}
The development of technology and communication has brought many changes, especially in broadcast industry. Since the internet era, people could listen to music through various media portals that they accessed through smartphones. This trend is known as media convergence, where there is an interlacing between internet and radio. The birth of media convergence in radio industry also gave rise to the term of 'streaming', where the content broadcasted live through the internet, in the form of audio and video. One of the streaming radio service providers in Indonesia is JOOX. This scientific work's aim is to provide an overview and contribution to the era of new media, especially for music and radio industry. The concept of online strategy in music radio programming from Newton and Kaiser is being used. The result showed that JOOX is an audio visual based live streaming program that facilitates musicians to promote their new albums, as well as the place to interact with their fans through the live-chat feature as a form of engagement.
\end{abstract}

Keywords - Media convergence, radio industry, music industry, internet, live streaming 


\section{PENDAHULUAN}

Musik menjadi salah satu hiburan yang mendasar bagi manusia di era globalisasi saat ini. Seperti yang dikatakan oleh McQuail bahwa industri musik merupakan salah satu produk dari media massa (2011) yang erat kaitannya dengan media penyiaran radio, dimana pengguna dapat mendengarkannya secara fleksibel dimana dan kapan saja. Jika dulu orang mendengarkan acara musik di radio dengan format acara yang telah siap disajikan oleh penyiar, namun saat ini lanskap telah berubah semenjak era digital dan internet berkembang dengan munculnya istilah konvergensi media. Konvergensi merupakan wujud dari revolusi digital khususnya di Indonesia, dimana terjadinya integrasi dari berbagai jenis media ke dalam satu perangkat digital yang berkonsep satu saluran untuk beragam informasi (Hidayat, 2015). Era konvergensi juga memunculkan bentuk-bentuk bisnis media baru yang salah satunya adalah format live streaming di industri radio.

Live streaming adalah konten yang disiarkan langsung melalui media internet, dapat berupa video dan audio. Dengan menggunakan layanan ini, pengguna dapat mendengarkan radio hanya dengan bermodalkan koneksi internet saja tanpa dikenakan biaya tambahan. Berkembangnya bisnis di industri radio, musik, dan internet dalam format live streaming ini menjadi peluang baru, khususnya bagi para pembuat konten dan musisi seluruh dunia dari berbagai umur, kalangan, bahkan dari musisi baru hingga musisi profesional untuk dapat mempromosikan karyanya. Distribusi yang luas dan murah bahkan gratis semakin terbuka lebar sehingga menimbulkan keinginan orang-orang untuk terus berkarya lalu dibagikan melalui internet.

Digitalisasi musik dan radio live streaming saat ini sudah menjadi kanal pengguna untuk berkarya maupun untuk dikonsumsi. Di Indonesia, telah hadir layanan musik streaming yang dapat diakses oleh pengguna dengan gratis, yaitu JOOX. Dibuat pada bulan Oktober 2015 dan telah memiliki sebanyak 10 juta pelanggan. JOOX menyediakan layanan musik gratis dan legal dengan akses kuota murah. JOOX juga telah bekerj a sama dengan perusahaan rekaman di Indonesia untuk menghadirkan musik berkualitas yang memiliki lisensi resmi.

JOOX memiliki fitur antara lain menonton video klip dan rekaman video wawancara, yang produksinya dibuat sendiri. Dalam hasil riset riset internal JOOX, penggunanya didominasi anak muda berusia 18-24 tahun yang mengakses lewat platform Android, dengan waktu akses terbanyak di jam 19.00 hingga 22.00. Dari penjelasan diatas, peneliti tertarik untuk memaparkan konsep pembuatan acara Live Streaming "Joox Live Now" untuk memberikan gambaran dari kovergensi media sebagai wujud kontribusi bisnis media di era digital, khususnya pada industri musik dan radio.

\section{METODE PENELITIAN}

Metode perencanaan karya ilmiah ini dibagi dalam 2 bagian, yaitu riset dan programming.

1. Riset dilakukan secara kualitatif dengan melakukan wawancara bersama Girindra Prabowo selaku General Manager Content Department dari JOOX serta data sekunder berupa dokumen internal perusahaan.

\section{Radio Programming}

Programming merupakan pengorganisasian program, yang dalam hal ini adalah siaran radio yang dibuat sebaik mungkin sehingga tetap menarik dan menjaga ketertarikan pendengarnya (Marhamah, 2018). Dalam hal ini, program yang akn disajikan dengan menggunakan bantuan koneksi internet, maka strategi yang digunakan berupa konten yang sedang tren, video, dan audio. Seperti halnya menyediakan layanan pencarian musik yang digemari oleh pengguna dan memberikan tema-tema tersendiri yang disesuaikan dengan kebutuhannya di segala suasana (Newton dan Kaiser, dalam Eastman dan Ferguson, 2012). Langkah-langkah produksinya adalah sebagai berikut (Marhamah, 2016): 1) Menentukan dan identifikasi ide, 2) Pengumpulan bahan, 3) Menentukan format acara, dan 4) Membuat kerangka. 


\section{HASIL DAN PEMBAHASAN}

Sebagai aplikasi music streaming, JOOX berupaya untuk terus menarik peminat dan membangun kedekatan dengan para penggunanya, baik musisi maupun penikmat konten. Dengan tampilan audiovisual dan fitur live-chat, hal ini dapat mendekatkan artis dengan idolanya. Di setiap tampilannya, JOOX memberikan sentuhan yang menunjukan karakteristik dan nilai sesuai dengan tampilan aplikasi seperti logo dan warna yang digunakan, salah satu bentuk komunikasi yang digunakan dengan menampilkan foto kegiatan yang sedang berlangsung maupun yang akan datang berupa e-poster di media sosial.

Sebelum JOOX Live Now tayang, tim media sosial akan mengunggah e-poster yang merupakan materi promosi berupa musisi yang akan tampil pada JOOX Live Now minggu ini. Selain bertujuan untuk mendapatkan daya tarik terhadap konsumen, e-poster diberikan caption dan hashtag (\#) yang berkaitan dengan konten, sehingga potensi penonton dapat mudah mencari akun Instagram serta informasi JOOX Live Now hanya dengan mengetik kata kunci hastag (\#) terkait e-poster coming soon.

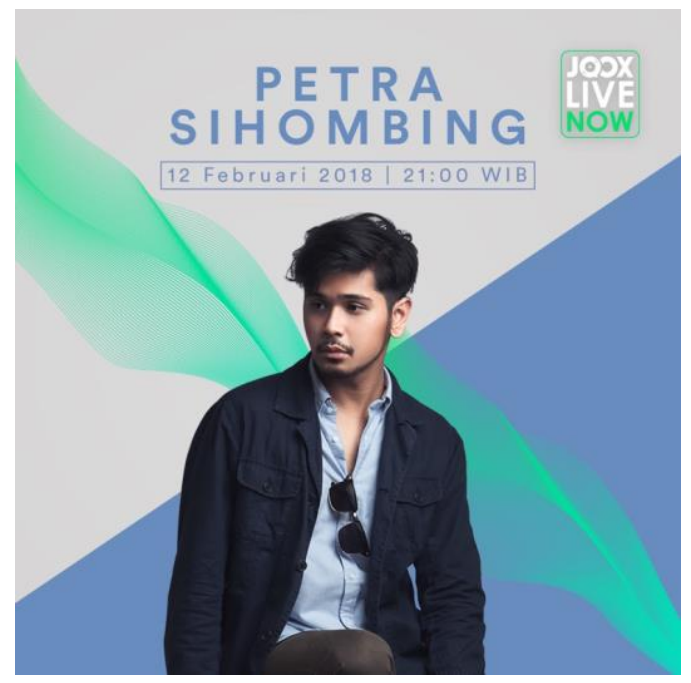

Gambar 1 Contoh e-poster

Sebagai implementasi visual, warna dan logo JOOX terdiri dari perpaduan warna hijau, putih dan hitam. Dimana hitam melambangkan kekuatan, kemewahan, dan kesan elegan, serta warna putih melambangkan kemurnian, bersih dan memberikan kesan kontras, kemudian hijau pada lambang piringan hitam melambangkan bahwa aplikasi JOOX memiliki ramah data, tidak boros saat pemakaian.

Logo JOOX Live Now dibuat secara khusus dalam bentuk font yang diambil dari perpaduan lambang piringan hitam yang mencerminkan sebuah benda yang berisikan kumpulan lagu jika dipasangkan dengan alat yang tepat untuk memutar lagu dari piringan hitam tersebut kemudian dipadupadankan dengan arial bold yang sudah diolah merupakan jenis font yang tergolong dalam kategori yang san- serif terbilang besar dan cukup jelas serta mudah dibaca. Pemilihan model tulisan century gothic bold pada logo JOOX bertujuan untuk memberikan kesan tegas namun tetap terlihat ekslusif, artistic, dan professional, selain itu juga jenis tulisan gothic tersebut mudah untuk dibaca dan memiliki bentuk yang tegas. 


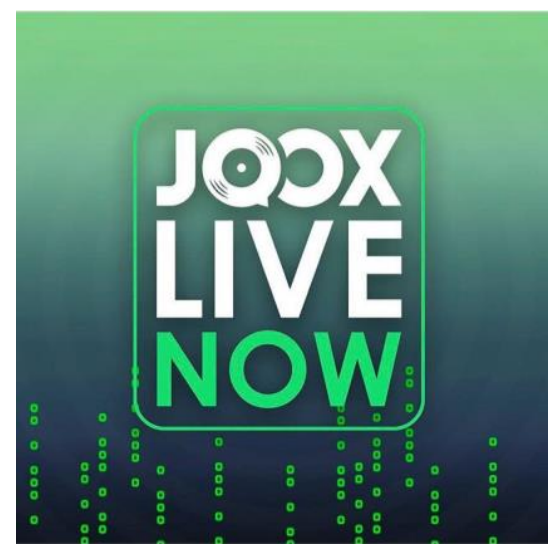

Gambar 2 Visualisasi Joox Live Now

Pemilihan warna logo JOOX Live Now menggunakan perpaduan warna dominan hijau, putih dengan background gradasi hijau muda dan gelap. Dimana warna putih melambangkan kemurnian, bersih dan memberikan kesan jelas, kemudian hijau melambangkan bahwa aplikasi Joox memiliki ramah data, tidak boros saat pemakaian ketika mengakses JOOX Live Now.

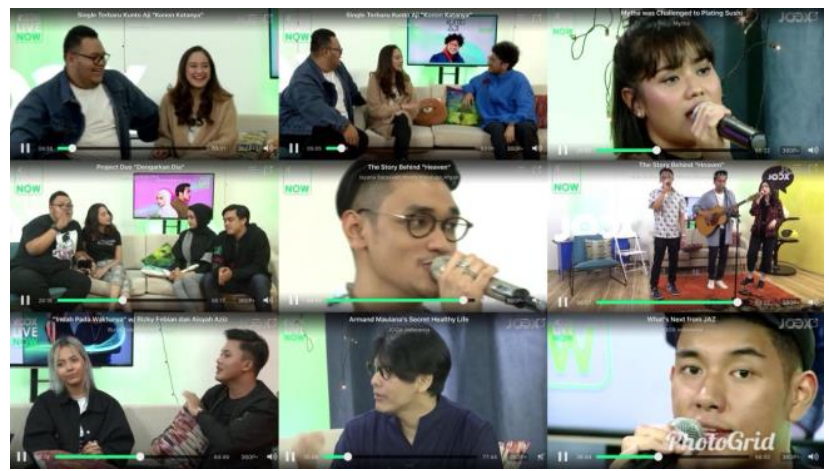

Gambar 3 Tata ruang siaran

Dalam hal atmosfir, tata ruang siaran didesain sedemikian rupa untuk mempromosikan konten. Dengan perpaduan warna merah, hijau, dan cokelat, interior JOOX Live memberikan kesan yang ceria. Selanjutnya dalam pemilihan jam tayang, tim produksi awalnya mengadakan acara pilot project untuk meninjau jam tayang mempunyai jumlah penonton yang banyak. Setelah mencoba 3 jam tayang yaitu jam 18.00, 19.00, dan 21.00 WIB, terbukti pukul 21.00 WIB adalah waktu yang bisa membawa angka yang besar. Maka dari hasil percobaan ini lah maka ditetapkan jam tayang untuk JOOX Live Now adalah pukul 21. 00 WIB dengan durasi selama satu jam hingga pukul 22.00 WIB.

Hal ini juga didukung dengan pemanfaatan sosial media, salah satunya Instagram. Dimana media ini memiliki fitur dalam membagikan gambar yang dapat diunggah secara multiple photos dalam satu konten yang diunggah dan fitur video. Selain itu juga Instagram memiliki fitur untuk memberikan keterangan pada konten yang diunggah, hashtag (\#), mention(@), dan tag yang menghubungkan ke akun lainnya. Pemilihan akun utama Instagram dengan nama JOOX Live Now dipilih agar dapat mempermudah konsumen untuk mencari informasi JOOX Live Now dengan mudah. Selain Instagram, pesan notifikasi pada aplikasi juga menjadi upaya mempromosikan program, agar pengguna memiliki pilihan ketika sedang berada di dalam aplikasi, tidak hanya memilih lagu yang telah disediakan didalamnya melainkan juga bisa menikmati tampilah visual yang disediakan. 
Dari segi peralatan produksi, tim menggunakan 3 buah kamera, yaitu di sisi kanan, tengah dan kiri studio. Pada sisi kanan dan kiri untuk mengambil detail talent saat berbicara sedangkan tengah untuk mengambil gambar keseluruhan layout studio serta talent. Kamera yang digunakan yaitu Sony XE3 dengan alasan spesifikasi yang dimiliki PMW-EX3 telah didukung oleh layar monitor berukuran 3,5 inci yang mampu menangkap banyak warna. Sedangkan lensa yang digunakan adalah jenis EX mount dengan focal length mencapai $81,2 \mathrm{~mm}$.

Dalam hal pemandu acara, Reza Chandika dan Salshabilla Adriani lah yang terpilih untuk bertanggung jawab dalam menghidupkan suasana serta menghibur para penonton. Alasan dipilihnya Reza Chandika karena ia memiliki karakter yang kuat dalam segi humor dan selalu menyajikan candaan yang sesuai dengan target audience. Ia juga merupakan seorang peyiar radio di Jakarta. Reza memiliki 58 ribu pengikut di akun Instagram pribadi nya dan konten yang dibuat oleh Reza sangat menarik dan menghibur. Sedangkan Salshabilla terpilih menjadi pemandu acara JOOX Live Now untuk merepresentasikan generasi millenials, dikarenakan target market yang dimiliki JOOX berusia 15-25 tahun maka Salshabilla dianggap merupakan sosok yang pas menjadi pemandu acara. Selain itu, menurut hasil meeting internal, pengikut yang banyak di akun Instagram pribadi Salshabilla juga menjadi faktor pendukung yang kuat untuk bisa menggiring pengikutnya untuk menonton acara JOOX Live Now.

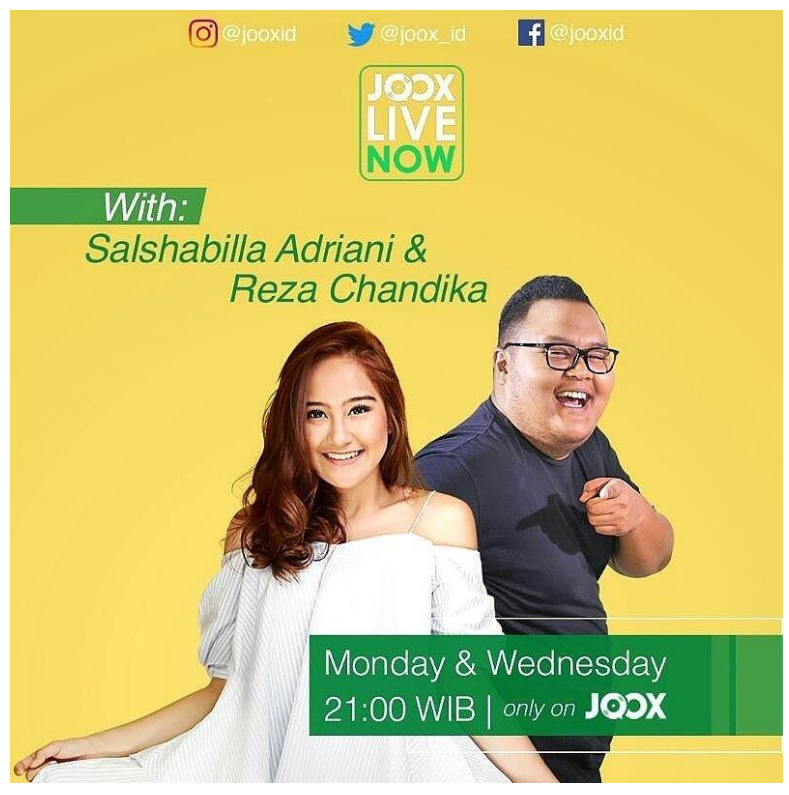

Gambar 4 Pembawa acara Joox Live Now

\section{KESIMPULAN}

Simpulan dari karya ini adalah Konsep pembuatan acara JOOX Live Now diharapkan dapat memberikan inspirasi dan pilihan untuk pengguna di era industri media digital sekarang ini. Dimana pengguna dapat menentukan sendiri acara dan musik sesuai dengan selera maupun pilihannya. Dengan bantuan media sosial juga, program ini memfasilitasi para musisi untuk mempromosikan album barunya, serta ajang untuk saling berinteraksi dengan penggemarnya lewat fitur live-chat sebagai wujud dari engagement. Diharapkan untuk pembuatan karya selanjutnya agar dapat banyak lagi memunculkan inovasi-inovasi yang sesuai dengan tren. Hasil evaluasi dari program menunjukan bahwa semakin terkenal artis yang diundang ke acara live streaming, maka jumlah viewers akan semakin tinggi jumlahnya. Hal ini dapat menjadi peluang untuk industri iklan digital dan dapat diukur efektivitasnya dalam penelitian selanjutnya. 


\section{UCAPAN TERIMAKASIH}

Segenap rasa terimakasih kami haturkan kepada JOOX dan Tencent Media, serta STIKOM LSPR Jakarta.

\section{DAFTAR PUSTAKA}

Eastman, S. T. and Ferguson, D. A. (2012). Media Programming: Strategies and Practices. Boston: Cengage Learning

Hidayat, R. (2015). Analisis Manajemen Penyiaran di Era Teknologi Informasi (Konvergensi Media). Jurnal Konvergensi Vol. 01 No. 01 Januari 2015 Universitas Paramadina

Marhamah. (2016). Produksi Siaran Radio dan Film. Lhoksmawe: Mueeza

McQuail, D. (2011). Teori Komunikasi Massa McQuail Edisi 6 Buku 1. Jakarta: Salemba Humanika 